\title{
A Case of Clozapine Induced Acute Renal Failure
}

\author{
Na Young An, Jeewon Lee and Jai Sung Noh ${ }^{凶}$ \\ Department of Psychiatry \& Behavioral Sciences, Ajou University School of Medicine, Suwon, Republic of Korea
}

There have been a few case reports that clozapine, an atypical antipsychotic, caused acute renal failure of interstitial type. Here we report a case of a 38-year-old Korean male patient with treatment-resistant bipolar I disorder who developed acute renal failure after the initiation of treatment with clozapine. We describe the clinical and laboratory findings of the case and discuss the measures for early detection of this life threating condition. Within our knowledge, this is the first report of clozapine-induced acute renal failure in South Korea.

Psychiatry Investig 2013;10:92-94

Key Words Clozapine, Acute renal failure, Interstitial nephritis, Bipolar I disorder.

\section{INTRODUCTION}

In spite of its advantage in controlling psychotic symptoms, clozapine has been used as a second-line antipsychotic drug due to its potentially life-threatening side effect, agranulocytosis. ${ }^{1}$ Recently, a few cases of clozapine-induced acute renal interstitial nephritis have been reported in the western countries but not in Korea. ${ }^{2-4}$ We report a case of acute renal failure developed just after initiation of clozapine for the treatment of mood symptom in a young male patient.

\section{CASE}

The adverse reaction to clozapine occurred in a 38-yearold Korean male patient with treatment-resistant bipolar I disorder. He was diagnosed with bipolar I disorder at around the age of 19 and had been treated with many different antipsychotics over the past 20 years. His last medication before clozapine was lithium, valproate and risperidone which brought his mood symptom into remission. However, during his outpatient clinic follow-up, he continuously complained of hand tremor and eventually lithium was stopped. Then his mood

Received: April 22, 2012 Revised: July 26, 2012

Accepted: August 1, 2012 Available online: February 8, 2013

$\triangle$ Correspondence: Jai Sung Noh, MD

Department of Psychiatry \& Behavioral Sciences, Ajou University School of Medicine, 164 Worldcup-ro, Yeongtong-gu, Suwon 443-721, Republic of Korea

Tel: +82-31-219-5180, 5183, Fax: +82-31-219-5179, E-mail: jsnoh@ajou.ac.kr (a) This is an Open Access article distributed under the terms of the Creative Commons Attribution Non-Commercial License (http://creativecommons.org/licenses/bync/3.0) which permits unrestricted non-commercial use, distribution, and reproduction in any medium, provided the original work is properly cited. became elated and he had to be hospitalized for the treatment of his manic episode. After being hospitalized, he received higher dosages of valproate and risperidone, but his manic symptom showed no improvement even after a month. Finally, medication change to clozapine was decided. Anti-manic effect of clozapine monotherapy has been confirmed by several clinical trials (Kimmel et al., 1994; Frye et al., 1998; Suppes et al., 1999). When 22 patients with bipolar disorder were treated to clozapine monotherapy, $77.3 \%$ showed response. ${ }^{5} 60$ patients diagnosed with treatment resistant bipolar disorders and schizoaffective disorders were treated with clozapine monotherapy and the response rate was $60 \%$ after 6 months and $83 \%$ after 2 years. ${ }^{6}$ Therefore, we decided this patient should be treated with clozapine monotherapy, as it was a case of treatment resistant bipolar I disorder patient. Clozapine was started from $12.5 \mathrm{mg}$ and were increased up to $200 \mathrm{mg}$ in 14 days. On the 14 th day, the patient developed hyperthermia $\left(39.2^{\circ} \mathrm{C}\right)$ which was subsided after 6 days. On the 19th day, he suddenly gained $8 \mathrm{kgs}$ of weight, and developed generalized edema and urinary difficulty. On laboratory results, he showed signs of acute renal failure: $\mathrm{CBC}$ results showed no eosinophilia but WBC was checked 15300/uL, and routine chemistry showed BUN 32.3 $\mathrm{mg} / \mathrm{dL}$, creatinine $4.1 \mathrm{mg} / \mathrm{dL}$, ESR $35 \mathrm{~mm} / \mathrm{h}$ and CRP 29.74 $\mathrm{mg} / \mathrm{dL}$. Protein $2+$, blood $3+, \mathrm{RBC}$ and $\mathrm{WBC}$ were found in urine analysis.

No specific finding was found in EKG and echocardiography. Abdomen CT showed diffuse bowel wall thickening with some distension, minimal enterocolitis and diffuse swelling of both kidneys which were evidences for ARF. Chest Xray showed atelectasis and pleural effusion at both of his lower 
lungs.

Immune antibody test showed no evidence systemic disease, and the blood and urine culture were negative. Renal biopsy was not performed due to patient's refusal. The only medication that was recently changed was clozapine, and lithium and valproate level were all within therapeutic range. Under the impression of acute renal failure due to clozapine, clozapine was stopped and the patient received hemodialysis 6 times a week. In 10 days, the patient could self-urinate and laboratory results showed normalized kidney function with BUN $20.7 \mathrm{mg} / \mathrm{dL}$ and creatinine $1.2 \mathrm{mg} / \mathrm{dL}$. Even though renal biopsy couldn't be performed due to patient's refusal, diagnosis of acute renal failure induced by clozapine could be made under clinical circumstances.

\section{DISCUSSION}

FENa is needed for the diagnosis of differentiating subtype when patient is suspected of being in a state of acute renal failure with elevated Creatinine level. ${ }^{7}$ By evaluating sodium fraction in urine, we could determine whether the acute renal failure is of pre-renal or renal (intrinsic) type and assess the concentrate ability of kidney. ${ }^{8}$

Low fractional excretion $(<1 \%)$ indicate sodium retention by the kidney, such as volume depletion or decreased effective circulating volume $e^{7}$ (e.g., low output heart failure). Higher values ( $>2 \%$ ) suggest sodium wasting due to acute tubular necrosis or other causes of intrinsic renal failure. The current patient's $\mathrm{FE}_{\mathrm{Na}}$ was calculated as 2.16 (\%), indicating intrinsic renal failure.

Despite his lack of biopsy results, the patient improved readily after withdrawal of a potentially offending drug. We could find proteinuria and pyuria but no red blood cell cast or dysmorphic red blood cell indicating glomerular disease. Also he was not anemic, hypertensive or showed abnormal vital sign. Therefore, after considering all the factors, we diagnosed him with intrinsic renal failure of interstitial type by clozapine.

Acute interstitial nephritis (AIN) is an important cause of acute renal failure and drug hypersensitivity reactions are the most common cause of AIN. Clozapine is a tricyclic dibenzodiazepine derivative anti-psychotic that differs from the classic neuroleptics. Clozapine has a strong effect of sedation and lowered seizure threshold. ${ }^{9}$ Among its adverse effects, the most serious adverse drug reaction is agranulocytosis. Uncommon adverse effects including hepatitis, pancreatitis, vasculitis, pneumonia and renal adverse event are less recognized. ${ }^{1}$ Infection related causes were excluded by negative blood and urine cultures, and systemic diseases known to be associated with AIN were excluded by negative serology for anti-nuclear, an- ti-neutrophil cytoplasmic, and anti-double stranded DNA antibodies negative rheumatoid factor. ${ }^{2}$

AIN is life-threatening allergic reaction that need close monitoring and finally diagnosed by biopsy. ${ }^{8}$ When the clozapine is started newly, the symptom and sign of clozapine-induced AIN are known to be occurring such as skin rash, fever, eosinophilia, tachycardia, proteinuria, sterile pyuria, arthralgia, elevated IgE and CRP. However, all of these symptoms do not appear at the same time because the heterogeneous clinical manifestations could be shown. AIN should be suspected if the symptom has been appeared according to time order after initiation of clozapine treatment, and if other drugs had been tolerant to the patient previously. ARF due to neuroleptic malignant syndrome is well known but the AIN due to atypical antipsychotics is limited to few case reports. ${ }^{10}$

ARF causes the electrolyte imbalance, and lowers the resistance to infection, and leads to blood-related disease such as anemia or platelet function. ${ }^{11}$ Also, gastrointestinal complications, for instance loss of appetite, nausea, vomiting, diarrhea or constipation, could be developed, and has the possibility of the uremic encephalopathy causes the blunting emotion, convulsion and coma. If hyperkalemia is not corrected, it might lead a heart attack. Signs of infection should be cautiously monitored and certain antibiotics such as aminoglycosides which have nephrotoxicity should be avoided. Although it is rarely reported, AIN should be regarded as important as agranulocytosis as clozapine's critical side effect.

\section{REFERENCES}

1. Taylor D, Paton C, Kerwin R. The Maudsley Prescribing Guidelines. 9th Edition. Informa Healthcare, 2007, p.73-75.

2. Elias TJ, Bannister KM, Clarkson AR, Faull D, Faull RJ. Clozapine-induced acute interstitial nephritis. Lancet 1999;354:1180-1181.

3. Au AF, Luthra V, Stern R. Clozapine-induced acute interstitial nephritis. Am J Psychiatry 2004;161:1501.

4. Hunter R, Gaughan T, Queirazza F, McMillan D, Shankie S. Clozapine-induced interstitial nephritis - a rare but important complication: a case report. J Med Case Rep 2009;3:8574.

5. Green AI, Tohen M, Patel JK, Banov M, DuRand C, Berman I, et al. Clozapine in the treatment of refractory psychotic mania. Am J Psychiatry 2000;157:982-986.

6. Ciapparelli A, Dell' Osso L, Pini S, Chiavacci MC, Fenzi M, Cassano GB. Clozapine for treatment-refractory schizophrenia, schizoaffective disorder, and psychotic bipolar disorder: a 24-month naturalistic study. J Clin Psychiatry 2000;61:329-334.

7. Schrier RW, Wang W, Poole B, Mitra A. Acute renal failure: definitions, diagnosis, pathogenesis, and therapy. J Clin Invest 2004;114:5-14.

8. Kodner CM, Kudrimoti A. Diagnosis and management of acute interstitial nephritis. Am Fam Physician 2003;67:2527-2534.

9. Layland JJ, Liew D, Prior DL. Clozapine-induced cardiotoxicity: a clinical update. Med J Aust 2009;190:190-192.

10. Strawn JR, Keck PE Jr, Caroff SN. Neuroleptic malignant syndrome. Am J Psychiatry 2007;164:870-876.

11. Bellomo R, Ronco C, Kellum JA, Mehta RL, Palevsky P; Acute Dialysis Quality Initiative workgroup. Acute renal failure - definition, outcome measures, animal models, fluid therapy and information technology 
needs: the Second International Consensus Conference of the Acute Dialysis Quality Initiative (ADQI) Group. Crit Care 2004;8:R204R212.

12. Kanofsky JD, Woesner ME, Harris AZ, Kelleher JP, Gittens K, Jer- schow E. A Case of acute renal failure in a patient recently treated with clozapine and a review of previously reported cases. Prim Care Companion CNS Disord 2011;13. 